\title{
“People of Different Moral Convictions Cannot Get Along": The Effects of Perception of Colleague's Unethical Pro-Organization on Other Employees' Interpersonal Facilitation
}

\author{
Biyao Chen \\ Management School, Jinan University, Guangzhou, China \\ Email: 631642994@qq.com
}

How to cite this paper: Chen, B. Y. (2021). "People of Different Moral Convictions Cannot Get Along": The Effects of Perception of Colleague's Unethical Pro-Organization on Other Employees' Interpersonal Facilitation. Journal of Human Resource and Sustainability Studies, 9, 43-56.

https://doi.org/10.4236/jhrss.2021.91004

Received: January 26, 2021

Accepted: March 1, 2021

Published: March 4, 2021

Copyright $\odot 2021$ by author(s) and Scientific Research Publishing Inc. This work is licensed under the Creative Commons Attribution International License (CC BY 4.0).

http://creativecommons.org/licenses/by/4.0/

\begin{abstract}
Based on the theory of social information processing, this research discusses the relationship between the perception of unethical pro-organizational behaviors of colleagues and the interpersonal facilitation of third-party employees and their mechanism. The results show that the perception of unethical pro-organizational behaviors of colleagues affects employees' interpersonal facilitation by affecting employees' perception of ethical climate. Perceiving colleagues' unethical pro-organizational behaviors positively affects the self-interested ethical climate perception of the third-party employees, and negatively affects the caring and rules climate perception, resulting in employees' negative attitudes toward colleagues, thereby alienating colleagues and reducing interpersonal facilitation. This research not only enriches and expands the research on unethical pro-organizational behaviors from the theoretical development and research perspectives, but also provides some management inspiration for organizations.
\end{abstract}

\section{Keywords}

Unethical Pro-Organizational Behaviors, Self-Interested Ethical Climate,

Caring Ethical Climate, Rule-Based Ethical Climate, Interpersonal

Facilitation, Social Information Processing Theory

\section{Introduction}

With the rapid development of society and economy, competition among enterprises has become increasingly fierce. In order to obtain economic benefits and maintain market positions, many enterprises have adopted improper methods, 
such as tax evasion, false propaganda, bribery of customers and so on. These corporate scandals have confirmed corporate unethical behaviors are frequent and "popular" within certain companies (Frank et al., 2003). Research on unethical behaviors of companies pointed out that the motivation for employees' engaging in unethical behaviors may be seeking their own interests (e.g., Greenberg, 2002; Terpstra, Rozell, \& Robinson, 1993), revenging or harming the organization (e.g., Skarlicki \& Folger, 1997), hurting colleagues (e.g., Thau, Aquino, \& Poortvliet, 2007) and so on.

Thereinto, as a special kind of unethical behavior, the motivation of unethical pro-organizational behavior (UPB) is to benefit the organization (Umphress, Bingham, \& Mitchell, 2010). In recent years, there have been a large number of studies from the perspective of UPB's antecedents, studying the influence of factors such as leadership, organization, workplace, and individuals on unethical pro-organizational behavior (Graham et al., 2015; Zhang, Zhang, \& Zhao, 2017; Matherne \& Litchfield, 2012). Relatively speaking, the analysis of the consequences of UPB is still lacking. Part of the research involved UPB's impact objects include organizations (Ilie, 2012), individuals and stakeholders (Umphress \& Bingham, 2011). Some scholars have also studied the impact of leadership's UPB on perception and behaviors of employees based on a third-party perspective (Nguyen et al., 2019), and the impact of colleagues' UPB on other employees' behaviors. These studies of the third-party perspectives are all from the point of view of the perspective of social learning, exploring the positive identification and imitative learning of employees with the UPB of leaders and colleagues, but ignore the negative attitudes of other employees to UPB of leaders or colleagues. In terms of the "unethical" nature of UPB, does the UPB of a leader or colleague make other employees perceive a certain negative atmosphere in the organization? Does the perception of this atmosphere cause employees to alienate leaders and colleagues? This article will start from the theoretical perspective of social information processing, based on the theoretical core of the change of human behavior caused by environmental clues, and explore how third-party bystanders will interpret the social information and the organizational atmosphere transmitted by the UPB of colleagues in organizations, and what kind of interpersonal behaviors will be based on these interpretations.

\section{Theory and Hypothesis}

\subsection{Perception of Colleagues' UPB and Interpersonal Facilitation}

Unethical pro-organizational behavior (UPB) is a kind of spontaneous behavior aimed at promoting the effective operation of the organization or its members (such as leaders) that violates core social values, ethics, laws or reasonable standards of behaviors (Umphress \& Binghamp, 2011). UPB has the dual characteristics of "non-ethical" and "pro-organizational" (Umphress et al., 2010). Later, some scholars have proposed that UPB is not only for the purpose of obtaining 
organizational benefits, but also for the purpose of obtaining personal benefits from organizational benefits (Vadera et al., 2013). Based on the theory of social information processing, this research speculates that if other individuals in the organization perceive that colleagues in the organization are engaged in UPB, the interpersonal promotion behaviors of these individuals will decrease. The theory of social information processing points out that individual activities and behaviors do not take place in a vacuum, and are usually affected by complex and vague social situations (Salancik \& Pfeffer, 1978). The social environment provides a variety of information that affects individuals' attitude and behaviors, and their interpretation of this information determines subsequent attitude and behaviors. On the one hand, although the implementation of UPB can bring short-term benefits to the enterprise, it will bring potential, negative and destructive effects to the organization in the long run (Ilie, 2012). The employees who implement UPB have short-term orientation and persist in short-term huge benefits, without considering that this behavior will bring disaster to the organization; on the other hand, the implementation of UPB by team members is likely to benefit from their contributions to the team, this behavior is not divorced from the perspective of egoism (Umphress et al., 2010). Based on this theory, when in the social situation of work, other individuals perceive the social information of colleagues implementing UPB, and then will have a negative interpretation of this behavior of colleagues: first, the behavior of this colleague is unethical, damaging not only the interest of society, but also the image and reputation of the organization, which is a short-sighted behavior that is not for the long-term development of the organization; second, the colleague's apparent pro-organizational behavior is actually for the benefit of the individual, which is venal and selfish. Interpersonal facilitation refers to the degree to which employees are helpful, considerate and cooperative to others at work (Van Scotter \& Motowidlo, 1996). The theory of social information processing points out that individual activities and behaviors will be affected by the interpretation of social information (Frazier \& Bowler, 2015). When perceiving UPB of colleagues in the organization, other individuals make the above two negative interpretations, which will produce resistance to colleagues, lead to alienation and contact advoidance with colleagues, reduce help or care and cause a decrease in interpersonal promotion among colleagues. Therefore, we propose:

H1: Perception of colleagues' UPB negatively affects employees' interpersonal facilitation.

\subsection{The Mediation Role of Ethical Climate}

Organizational Ethical Climate (Organizational Ethical Climate) is included in the category of organizational climate. It is the perception that all members form when dealing with ethical dilemmas or facing ethical behavior choices. It is a reflection of the internal dominant ethical behavior model (Victor \& Cullen, 1987). There are many types of organizational ethical atmospheres proposed by 
scholars in previous studies, but currently only three types of ethical atmospheres have been verified, namely: self-interested, caring, and rule-based ethical atmospheres (Martin \& Cullen, 2006). The self-interested ethical atmosphere means that the behavioral decisions of the members of the organization are mainly to serve personal interests and often cause damage to the organization and others for their own interests; the caring ethical atmosphere means that the members of the organization value the interests of all stakeholders and will consider to the consequences that individual actions may bring to others; the rule-based ethical atmosphere means that the members of the organization strictly abide by the code of conduct and ethics, organizational rules and regulations.

The theory of social information processing points out that the social environment in which an individual is located has information to describe the characteristics of the work environment. The social environment attracts individual attention by highlighting certain aspects of social information (Skarlicki \& Folger, 1997). Employees' perception and interpretation of acceptable behaviors are affected by various sources of information (Miller \& Monge, 1985). Based on this, people can better evaluate the surrounding work environment (Salancik \& Pfeffer, 1978). Self-interested ethical atmosphere-oriented organizations encourage employees to proceed from their interests in everything, and this kind of interest includes not only personal interests, but also fighting for interests of the organization (Wimbush, Shepard, \& Markham, 1997). According to the theory of social information processing, when colleagues in an organization defy ethical guidelines for organizational or personal benefit, and do not consider the impact on society, conducting unethical pro-organizational behaviors, other employees who receive this organizational behavioral information will perceive that the implemention of non-ethical behaviors for organizational or personal interests are permitted, which will perceive the dense self-interested ethical atmosphere. The caring ethical atmosphere emphasizes the balance of interests of all stakeholders. When considering themselves, they also consider the gains and losses of the company and even the stakeholders (Zhang, 2014). Organizations value the contributions made by employees, require leaders to care for and show consideration for employees, and hope that employees will help each other (Liu \& Jing, 2010). The implementation of UPB by colleagues will cause harm to other stakeholders in the society. The interests of all stakeholders are imbalanced. The organization also has an atmosphere of loss of moral bottom line and selfishness. Therefore, other employees in the organization will feel that the caring organizational atmosphere and the image of company have been destroyed. Perceiving that colleagues implement UPB will cause other employees to perceive a weakening of the caring ethical atmosphere. The rule-based ethical atmosphere emphasizes that employee compliance and discipline are the top priority, and rules are the first priority (Yuan and Liu, 2016). The organization will establish a standardized charter based on specific conditions and hope that employees will act in accordance with the rules (Takeuchi et al., 2012), requiring employees to 
strictly abide by professional ethics and social ethics and not to violate the rules for the benefit of the organization (Nedkovski et al., 2017). Based on this, when colleagues in the organization violate professional ethics and implement unethical pro-organizational behaviors, other employees will be affected by this behavioral information, and they will make negative interpretations of their violations of rules, regulations and social ethics, thus perceiving that the rule-based ethical atmosphere in the organization is destroyed. Therefore we propose:

H2: The implementation of UPB by colleagues negatively affects employees' perception of caring ethical atmosphere;

H3: The implementation of UPB by colleagues negatively affects employees' perception of a rule-based ethical atmosphere;

H4: The implementation of UPB by colleagues positively affects employees' perception of self-interested ethical atmosphere.

The theory of social information processing further proposes that activities and behaviors of individuals do not occur in a vacuum, but are usually affected by complex and vague social situations. The social environment in which individuals live provides various information that affects their attitudes and behaviors., Individuals' interpretations of this information determines subsequent attitude and behavior (Salancik \& Pfeffer, 1978). The norms of behavior in the workgroup are consolidated in a specific atmosphere (Wallace, Popp, \& Mondore, 2006), resulting in a stronger connection between the specific atmosphere and the results of specific interests (Schneider \& Bowen, 1993). Some studies have pointed out that in the ethical atmosphere of self-interested organizations, the quality of social networks constructed in organizations is poor. Based on this, we believe that employees perceive the increased self-interested ethical atmosphere in the organization, the prevalence of organizational self-interest, and colleagues seeking benefits for the organization and neglecting professional ethics, which will adversely affect the society, which will affect the quality of the organization's social network. The quality of interpersonal relationship has a negative impact. Other employees will feel that they lack a sense of dependence on the organization (Tajfel, 1986), and will have a negative attitude towards this behavior, gradually alienating these colleagues and reducing their interpersonal promotion behavior. A strong caring ethical atmosphere will lead to higher out-of-role behaviors of employees. They not only complete the normative behavior prescribed by the organization (Tang \& Pan, 2010). When the caring ethical atmosphere within the organization becomes weaker, employees will not only I rarely feel the "big love" and humanitarian care of the organization, and I also feel that the organization is gradually ignoring the balance of interests of all parties. Employees who feel the weakening of this atmosphere will also have fewer off-role behaviors, and interpersonal promotion behavior, as one of the off-role behaviors (Van Scotter \& Motowidlo, 1996), will also decrease, and employees will gradually alienate their colleagues. Unwilling to help, care and considerate colleagues in this indifferent atmosphere. If employees perceive the 
weakening of the rule-based ethical atmosphere, they will feel that the constraints of ethics, ethics, and company rules and regulations are invalid, and do not take social norms and legal systems into consideration. Therefore, they will develop negative attitudes on the organization, espacially the colleague who has implemented UPB, gradually alienating colleagues, and unwilling to provide help or care for and considerate colleagues. Therefore we propose:

H5: Employees perceive a weakening of the caring ethical atmosphere, which will lead to a decrease in their interpersonal facilitation;

H6: Employees perceive a weakened rule-based ethical atmosphere, which will lead to a decrease in their interpersonal facilitation;

H7: Employees perceive the strengthening of self-interested ethical atmosphere, which will cause their interpersonal facilitation to decrease;

H8: Self-interested ethical atmosphere, caring ethical atmosphere, and rule-based ethical atmosphere play an intermediary role between the perception of UPB of colleagues and interpersonal facilitation of employees.

Based on the above research hypotheses and inferences, this research proposes an intermediary adjustment model, as shown in Figure 1.

\section{Sample and Measures}

This study adopted a convenient sampling method, and distributed 350 questionnaires in 18 provinces across the country, and the recipients were in-service personnel. Data were collected at two-time points by questionnaire survey, and through the end of the phone number and the first letter of the name to match. Firstly, data on demographic information, perceived UPB of colleagues and ethical atmosphere was collected (Time 1), a total of 360 questionnaires were distributed, after deleting invalid questionnaires, 330 of which were valid. One month later (Time 2), data collection on interpersonal facilitation was carried out, A total of 330 questionnaires were distributed, after deleting invalid questionnaires, 309 of which were valid, 287 questionnaires were finally retained after deleting the questionnaires that were difficult to match with Time 1.

In order to obtain the scale suitable for this study, all scales were translated from English to Chinese and back-translated, and has been compiled by domestic scholars and has been verified to be of good reliability and validity in previous studies.

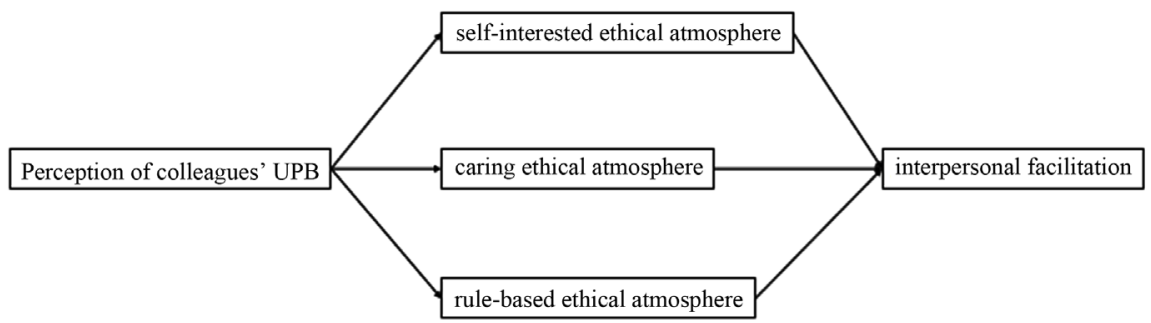

Figure 1. Theoretical model. 
Perceived colleague's unethical pro-organizational behavior: The unethical pro-organizational behavior questionnaire compiled by Umphress et al. (2010) and Matherne \& Litchfield (2012) includes 11 items. Since this study is conducted from a third-party perspective, the premise of the questionnaire was adapted to require the subjects to evaluate and judge their colleagues' unethical pro-organizational behaviors. A 6-point scoring system was adopted and the cronbach alpha coefficient in this study is 0.93 .

Organizational ethical atmosphere: The scale developed by Victor and Cullen (1987) is selected. The scale is divided into three dimensions: caring ethical atmosphere with 5 items; rule-based ethical atmosphere with 4 items; self-interested ethical atmosphere 5 items. Each dimension is scored with 6 points. The higher the score, the stronger the participants perceive this ethical atmosphere. The cronbach alpha coefficient in this study is 0.93 .

Interpersonal facilitation: A scale is used, including 7 items and a 5-point scoring method. The cronbach alpha coefficient in this study is 0.93 .

The research also collected information about the subjects' gender, age, working years, and education.

\section{Analyses and Results}

\subsection{Descriptive Statistics and Correlation Analysis}

Descriptive statistics and correlation analysis results are shown in Table 1 . Their mean age was $1.87(\mathrm{SD}=0.95)$, and their average duration of education was 2.60 $(\mathrm{SD}=0.90)$. Their average tenure was $2.23(\mathrm{SD}=1.06)$. The results in Table 2 show that the perception of colleagues' UPB and caring ethical atmosphere $(r=$ $-0.20, p<0.01)$, rule-based ethical atmosphere $(\mathrm{r}=-0.41, p<0.01)$, and

Table 1. Variable descriptive statistics and relevant analysis results $(\mathrm{N}=287)$.

\begin{tabular}{|c|c|c|c|c|c|c|c|c|c|c|c|}
\hline & $M$ & $S D$ & 1 & 2 & 3 & 4 & 5 & 6 & 7 & 8 & 9 \\
\hline 1. Gender & 1.54 & 0.50 & - & & & & & & & & \\
\hline 2. Age & 1.87 & 0.95 & 0.11 & - & & & & & & & \\
\hline 3. Education & 2.60 & 0.90 & -0.09 & $-0.18^{\star *}$ & - & & & & & & \\
\hline 4. Tenure & 2.23 & 1.06 & -0.09 & 0.04 & -0.10 & - & & & & & \\
\hline 5. UPB & 2.63 & 1.37 & 0.02 & -0.03 & 0.01 & $-0.14^{*}$ & $(0.97)$ & & & & \\
\hline 6. CA & 4.77 & 0.60 & -0.05 & $0.35^{\star \star}$ & -0.11 & 0.11 & $-0.20^{\star *}$ & $(0.61)$ & & & \\
\hline 7. RA & 4.91 & 1.04 & -0.10 & $0.29^{\star *}$ & -0.09 & 0.11 & $-0.41^{\star *}$ & $0.46^{\star *}$ & $(0.88)$ & & \\
\hline 8. SA & 3.10 & 1.56 & -0.01 & 0.08 & 0.02 & $-0.12^{*}$ & $0.64^{\star *}$ & -0.10 & $-0.27^{\star *}$ & $(0.95)$ & \\
\hline 9. IF & 3.78 & 1.12 & 0.04 & 0.10 & -0.06 & 0.08 & $-0.82^{\star *}$ & $0.24^{\star \star}$ & $0.42^{\star *}$ & $-0.59^{\star *}$ & $(0.93)$ \\
\hline
\end{tabular}

Note: $\mathrm{N}=287 ;{ }^{*} p<0.05 ;{ }^{*} p<0.01, \mathrm{UPB}=$ perceived UPB of colleagues; $\mathrm{CA}=$ Caring ethical atmosphere; $\mathrm{RA}=$ rule-based ethical atmosphere; $\mathrm{SA}=$ self-interested ethical atmosphere; IF = interpersonal facilitation. Gender: $1=$ male, $2=$ female, Age: $1=$ under 25, $2=25$ - 35, $3=35-45,4=$ above 45, Education: $1=$ senior high school and technical secondary school, 2 = junior college, $3=$ bachelor, $4=$ Master or above, Tenure: 1 $=$ under 1 year, $2=1-5$ years, $3=5-10$ years, $4=$ over 10 years. 
Table 2. Confirmatory factor analysis results $(\mathrm{N}=287)$.

\begin{tabular}{|c|c|c|c|c|c|c|c|}
\hline Model & $x^{2}$ & $d f$ & $\chi^{2} / d f$ & RMSEA & SRMR & CFI & NNFI \\
\hline 1) Five-factor model: UPB/CA/RA/SA/IF & 677.61 & 424 & 1.60 & 0.05 & 0.07 & 0.99 & 0.99 \\
\hline 2) Four-factor model: UPB/CA + RA/SA/IF & 735.57 & 428 & 1.72 & 0.05 & 0.08 & 0.99 & 0.99 \\
\hline $\begin{array}{l}\text { 3) Three-factor model: UPB/CA + RA + } \\
\text { SA/IF }\end{array}$ & 1438.64 & 431 & 3.34 & 0.11 & 0.17 & 0.97 & 0.96 \\
\hline $\begin{array}{l}\text { 4) Two-factor model: UPB + CA + RA + } \\
\text { SA/IF }\end{array}$ & 2255.87 & 433 & 5.21 & 0.15 & 0.20 & 0.94 & 0.93 \\
\hline $\begin{array}{l}\text { 5) One-factor model: UPB + CA + RA + SA } \\
+ \text { IF }\end{array}$ & 2619.43 & 434 & 6.04 & 0.16 & 0.20 & 0.93 & 0.92 \\
\hline
\end{tabular}

Note: UPB = perceived UPB of colleagues; $\mathrm{CA}=$ caring ethical atmosphere; $\mathrm{RA}=$ rule-based ethical at mosphere; $\mathrm{SA}=$ self-interested ethical atmosphere; $\mathrm{IF}=$ interpersonal facilitation.

employee interpersonal promotion behavior $(\mathrm{r}=-0.82, p<0.01)$ was negatively correlated, and positively correlated with self-interested ethical atmosphere $(\mathrm{r}=$ $0.64, p<0.01)$. Caring ethical atmosphere $(\mathrm{r}=0.24, p<0.01)$ and rule-based ethical atmosphere $(\mathrm{r}=0.42, p<0.01)$ are positively correlated with employees' interpersonal facilitation, and self-interested ethical atmosphere is negatively correlated with employees' interpersonal facilitation $(r=-0.59, p<0.01)$.

\subsection{Confirmatory Factor Analysis and Common Method Biases Test}

Through confirmatory factor analysis, this study examined the discriminant validity of perceived UPB of colleagues, caring ethical atmosphere, rule-based ethical atmosphere, self-interested ethical atmosphere and interpersonal facilitation. The results are shown in Table 2, where the five-factor model has the best fitting degree, RMSEA $<0.08$, CFI $>0.90$ and NNFI $>0.90$, so the above variables have good discriminant validity and represent four different constructs.

The homologous variance was tested by Harman single factor method, and the results showed that, without rotational precipitation, the variation explained by the first factor was $32.32 \%$, which was less than half of the total variance (76.04\%). Therefore, the common method biases will not cause serious impact in this study.

\subsection{Hypothesis Test}

Hierarchical regression was used to test the hypothesis in the study. The results are shown in Table 3, the model 4 shows that perceived UPB of colleagues significantly negatively predicted interpersonal facilitation $(\beta=-0.82, p<0.001)$, and the results support hypothesis 1 . The model 1 shows that perceived UPB of colleagues significantly negatively predicted caring ethical atmosphere $(\beta=$ $-0.07, p<0.001$ ), which supports hypothesis 2 . Moreover, the model 2 shows that perceived UPB of colleagues significantly negatively predicted rule-based ethical atmosphere $(\beta=-0.29, p<0.001)$, and the results support hypothesis 3 . The model 3 shows that perceived UPB of colleagues significantly positively 
Table 3. Hierarchical regression results.

\begin{tabular}{|c|c|c|c|c|c|c|c|}
\hline \multirow{3}{*}{ Variables } & \multicolumn{3}{|c|}{ Ethical Atmosphere } & \multicolumn{4}{|c|}{ Interpersonal Facilitation } \\
\hline & $\mathrm{CA}$ & RA & SA & \multirow{2}{*}{ M4 } & \multirow{2}{*}{ M5 } & \multirow{2}{*}{ M6 } & \multirow{2}{*}{ M7 } \\
\hline & M1 & M2 & M3 & & & & \\
\hline \multicolumn{8}{|c|}{ Control Variables } \\
\hline Gender & -0.08 & $-0.24^{\star \star}$ & -0.11 & 0.04 & 0.09 & 0.11 & 0.07 \\
\hline Age & $0.20^{\star * \star}$ & $0.29^{\star * *}$ & $0.18^{\star *}$ & 0.06 & 0.05 & 0.05 & $0.09^{* *}$ \\
\hline Education & -0.03 & -0.06 & 0.04 & -0.04 & -0.04 & -0.04 & -0.05 \\
\hline Tenure & 0.03 & 0.01 & -0.06 & -0.04 & -0.04 & -0.04 & -0.04 \\
\hline \multicolumn{8}{|c|}{ Independent Variable } \\
\hline UPB & $-0.07^{\star *}$ & $-0.29^{\star * *}$ & $0.73^{* * *}$ & $-0.82^{\star \star *}$ & $-0.66^{\star * *}$ & $-0.64^{* * *}$ & $-0.61^{\star * *}$ \\
\hline \multicolumn{8}{|c|}{ Mediating Variables } \\
\hline $\mathrm{CA}$ & & & & & $0.14^{\star \star}$ & & \\
\hline RA & & & & & & $0.10^{* *}$ & \\
\hline SA & & & & & & & $-0.09^{\star *}$ \\
\hline$R^{2}$ & 0.19 & 0.28 & 0.42 & 0.68 & 0.68 & 0.69 & 0.69 \\
\hline$\Delta R^{2}$ & - & 0.21 & - & - & 0.32 & 0.14 & - \\
\hline$F$ & $11.04^{* * *}$ & $18.15^{\star * *}$ & $34.15^{\star * *}$ & $118.61^{\star * *}$ & $85.97^{\star * *}$ & $86.80^{* * *}$ & $87.86^{* * *}$ \\
\hline
\end{tabular}

Note: The regression coefficients in the table are non-standardized. $\mathrm{N}=287 ;{ }^{* *} p<0.01 ;{ }^{* * *} p<0.001$. UPB $=$ perceived UPB of colleagues; $\mathrm{CA}=$ caring ethical atmosphere; $\mathrm{RA}=$ rule-based ethical atmosphere; $\mathrm{SA}=$ self-interested ethical atmosphere. Gender: $1=$ male, $2=$ female, Age: $1=$ under 25, $2=25-35,3=35-45$, $4=$ above 45 , Education: $1=$ senior high school and technical secondary school, $2=$ junior college, $3=$ bachelor, $4=$ Master or above, Tenure: $1=$ under 1 year, $2=1-5$ years, $3=5-10$ years, $4=$ over 10 years.

predicted self-interested ethical atmosphere $(\beta=0.73, p<0.001)$, which supports hypothesis 4 .

The model 5, 6, 7 shows that caring and rule-based ethical atmosphere significantly positively predicted interpersonal facilitation $(\beta=0.14, p<0.01 ; \beta=0.10$, $p<0.01$ ), and self-interested ethical atmosphere significantly negatively predicted interpersonal facilitation $(\beta=-0.09, p<0.01)$. Meanwhile, the negative effect of perceived UPB of colleagues on interpersonal facilitation is still significant $(\beta=-0.66, p<0.001 ; \beta=-0.64, p<0.001 ; \beta=-0.61, p<0.001)$. Therefore, the hypothesis 5, 6, 7 are supported and caring, rule-based and self-interested ethical atmosphere partially mediates the relationship between perceived UPB of colleagues and interpersonal facilitation.

The mediating effect of caring ethical atmosphere between perceived UPB of colleagues and interpersonal facilitation is -0.01 (bias correction CI $95 \%=$ $[-0.028,-0.001])$; The mediating effect of rule-based ethical atmosphere between perceived UPB of colleagues and interpersonal facilitation is -0.03 (bias correction CI $95 \%=[-0.065,-0.008])$; The mediating effect of self-interested ethical atmosphere between perceived UPB of colleagues and interpersonal facilitation is -0.07 (bias correction CI $95 \%=[-0.123,-0.022]$ ). According to the 
method, the sample number of bootstrap is 5000, and the test results support hypothesis 8 .

\section{Discussion}

This study found that: 1) Perceiving UPB of colleagues has a negative effect on employees' interpersonal facilitation; 2) The caring ethical atmosphere plays a partial mediating role in the relationship between the perception of colleagues' UPB and interpersonal facilitation; 3) The rule-based ethical atmosphere plays a partial mediating role in the relationship between perceiving colleagues' unethical pro-organizational behavior and interpersonal facilitation; 4) The self-interested ethical atmosphere plays a partial mediating role in the relationship between perceiving colleagues' unethical pro-organizational behavior and interpersonal facilitation.

This research expands the research perspective of UPB. Since unethical pro-organizational behaviors are voluntary behaviors that violate ethical guidelines but are beneficial to the organization to obtain short-term benefits, existing studies on pro-organizational unethical behaviors have mostly studied the antecedents or consequences of UPB from the first perspective, neglecting the feelings of the third-party employees in the context of the tripartite in organization. In the only relevant research, from the perspective of social learning theory, the researchers found that perceiving UPB by leaders or colleagues, the third-party employees will produce imitation and learning behaviors, which in turn will lead to the same behavior or other similar unethical behaviors. In fact, this conclusion reveals that the third party has a positive attitude towards the actions of UPB of other members, and they recognize or affirm such actions in their hearts, believing that such actions will not only bring short-term benefits to the company, but also gain benefits for themselves. From the theoretical perspective of social information processing, this research found that third-party employees will also have negative attitudes toward this behavior. The third-party employees will interpret colleagues' UPB from an unethical perspective, and this interpretation will affect their negative perception of the organization's ethical atmosphere, feeling the lower caring ethical atmosphere and rule-based ethical atmosphere, as well as the stronger self-interested ethical atmosphere, resulting in a sense of alienation from the organization or colleagues and leading to a decrease in the interpersonal facilitation. Therefore, this study expands the discussion of the impact mechanism of colleagues' implementation of UPB on third-party employees.

This study reveals the important psychological mechanism of third-party employees' feelings and behaviors towards colleagues implementing UPB. Organizational ethical atmosphere is the common cognition of organization members on the characteristics of the organization's ethical environment, and this kind of decision-making and behavioral intention is stable in each organization (Wan \& Zhu, 2006). This study focuses on the perception of organizational ethical atmosphere, and found that when colleagues implement UPB, third-party em- 
ployees will interpret the ethical environment of the organization. Moreover, starting from three kinds of ethical atmosphere perception, this study explores that perception of colleagues' UPB will affect ethical atmosphere from different directions, expanding the research path of the intermediary mechanism.

This research starts from the perspective of information processing and further explores the influencing mechanism of perceiving the colleagues' UPB on third-party employees. Third-party employees process and interpret the social information of colleagues' UPB, and then make a self-interpretation of the organization's ethical environmental characteristics, processing the environmental information and forming subsequent attitudes or behaviors.

The management enlightenment of this research lies in: First, organizations should correct their attitudes towards UPB. UPB may bring benefits to the organization in the short term, but in the long term, it will not only adversely affect the reputation and image of the organization, but also cause other employees to alienate the organization and its members, reducing loyalty and organizational recognition, which is not conducive to the smooth progress of interpersonal communication within the organization. Therefore, managers cannot implement such behaviors, let alone ignore, condone or even encourage such behaviors. Instead, they should resolutely combat all unethical behaviors and maintain the sustainable development of the enterprise. Secondly, the organization must strive to create a positive ethical atmosphere. First of all, the organization must prevent the formation and spread of a self-interested ethical atmosphere, strictly resist behaviors that harm others and self-interest in the organization, including unethical behaviors that are not only for themselves but also for the organization and alert employees to fairness and justice so that they may abide by ethics, guidelines and professional ethics. Additionally, organization should strengthen the construction of a rule-based ethical atmosphere and strive to create a caring ethical atmosphere. Organizations need to formulate and improve professional ethics systems, and always implement these systems to create a good atmosphere of rules. In addition, organizations should conduct professional ethics training, promote the spirit of love and humanitarianism, create a corporate culture of love and selflessness, and subtly lead employees to cultivate the spirit of caring for others. When non-ethical behaviors prevail, laws, regulations, organizational system specifications and a caring atmosphere can be used to restrain employees' non-ethical behaviors so that other employees can feel a positive ethical environment, reducing its negative interpretation of the organizational climate. Thirdly, the organization must create a friendly and healthy interpersonal atmosphere, build a multi-directional communication bridge for employees, maintain the positive development of interpersonal communication, and enhance employees' interpersonal facilitation. This is also crucial to the sustainable development of the company.

This study has the following limitations: 1) The questionnaire requires participants to report their perception of the UPB of their colleagues and the ethical atmosphere of the organization. Because of the sensitive information related to 
the moral aspects of their own organization, there may be a social praise effect and they are unwilling to answer truthfully. And homologous errors are inevitable. 2) This study lacks discussion on the boundary conditions of the negative psychological mechanism and behavior of the third-party employees towards colleagues' UPB. Third-party employees will disapprove their colleagues' UPB, which will result in a negative interpretation of the organization's ethical atmosphere. Such interpretation may be caused by the employee's personality traits or ethical concepts. Therefore, future research can explore how the employee's personality characteristics or values adjust the impact of UPB perception on the ethical atmosphere. 3) The questionnaire survey paradigm of this research has limitations, and it is impossible to fully determine the causal relationship between variables. It is recommended that future research can adopt a combination of questionnaires and experiments to further explore this issue to improve credibility.

\section{Conflicts of Interest}

The author declares no conflicts of interest regarding the publication of this paper.

\section{References}

Frank, R., Bryan-Low, C., Pacelle, M., Smith, R., Berman, D., Mollenkamp, C., \& Young, S. (2003). Scandal Scorecard. The Wall Street Journal, 242, B1-B4.

Frazier, M. L., \& Bowler, W. M. (2015). Voice Climate, Supervisor Undermining, and Work Outcomes: A Group-Level Examination. Journal of Management, 41, 841-863. https://doi.org/10.1177\%2F0149206311434533

Graham, K. A., Ziegert, J. C., \& Capitano, J. (2015). The Effect of Leadership Style, Framing, and Promotion Regulatory Focus on Unethical Pro-Organizational Behavior. Journal of Business Ethics, 126, 423-436. https://doi.org/10.1007/s10551-013-1952-3

Greenberg, J. (2002). Who Stole the Money, and When? Individual and Situational Determinants of Employee Theft. Organizational Behavior and Human Decision Processes, 89, 985-1003. https://doi.org/10.1016/S0749-5978(02)00039-0

Ilie, A. (2012). Unethical Pro-Organizational Behaviors: Antecedents and Boundary Conditions. Doctoral Dissertation, Tampa, FL: University of South Florida.

Liu, W. B., \& Jin, R. T. (2010). An Empirical Research of the Relationship between Organizational Culture and Counterproductive Behavior-The Perspective of Organizational Ethical Climate. China Soft Science Magazine, No. 9, 123-134+144.

Martin, K. D., \& Cullen, J. B. (2006). Continuities and Extensions of Ethical Climate Theory: A Meta-Analytic Review. Journal of Business Ethics, 69, 175-194. https://doi.org/10.1007/s10551-006-9084-7

Matherne, C. F., \& Litchfield, S. R. (2012). Investigating the Relationship between Affective Commitment and Unethical Pro-Organizational Behaviors: The Role of Moral Identity. Journal of Leadership, Accountability, and Ethics, 9, 35-46.

Miller, K. I., \& Monge, P. R. (1985). Social Information and Employee Anxiety about Organizational Change. Human Communication Research, 11, 365-386. https://doi.org/10.1111/j.1468-2958.1985.tb00052.x 
Nedkovski, V., Guerci, M., De Battisti, F., \& Siletti, E. (2017). Organizational Ethical Climates and Employee's Trust in Colleagues, the Supervisor, and the Organization. Journal of Business Research, 71, 19-26. https://doi.org/10.1016/j.jbusres.2016.11.004

Nguyen, C. M., Zhang, L., \& Morand, D. (2019). The Effect of Managers' Unethical Pro-Organizational Behavior (UPB) on Subordinates' UPB. Academy of Management Annual Meeting Proceedings, 2019, Article ID: 11643. https://doi.org/10.5465/AMBPP.2019.11643abstract

Salancik, G. R., \& Pfeffer, J. (1978). A Social Information Processing Approach to Job Attitudes and Task Design. Administrative Science Quarterly, 23, 224-253. https://doi.org/10.2307/2392563

Schneider, B., \& Bowen, D. E. (1993). The Service Organization: Human Resources Management Is Crucial. Organizational Dynamics, 21, 39-52. https://doi.org/10.1016/0090-2616(93)90032-V

Skarlicki, D. P., \& Folger, R. (1997). Retaliation in the Workplace: The Roles of Distributive, Procedural, and Interactional Justice. Journal of Applied Psychology, 82, 434-443. https://doi.apa.org/doi/10.1037/0021-9010.82.3.434

Tajfel, H. (1986). The Social Identity Theory of Intergroup Behavior. Psychology of Intergroup Relations, 13, 7-24.

Takeuchi, R., Chen, Z., \& Cheung, S. Y. (2012). Applying Uncertainty Management Theory to Employee Voice Behavior: An Integrative Investigation. Personnel Psychology, 65, 283-323. https://doi.org/10.1111/j.1744-6570.2012.01247.x

Tang, C. Y., \& Pan, Y. (2010). The Impact of Emotional Intelligence and Organizational Identification on Organizational Citizenship Behavior: A Multilevel Analysis. Nankai Business Review, No. 4, 115-124.

Terpstra, D. E., Rozell, E. J., \& Robinson, R. K. (1993). The Influence of Personality and Demographic Variables on Ethical Decisions Related to Insider Trading. Journal of Psychology, 127, 375-389. https://doi.org/10.1080/00223980.1993.9915573

Thau, S., Aquino, K., \& Poortvliet, P. M. (2007). Self-Defeating Behaviors in Organizations: The Relationship between Thwarted Belonging and Interpersonal Work Behaviors. Journal of Applied Psychology, 92, 840-847. https://doi.apa.org/doi/10.1037/0021-9010.92.3.840

Umphress, E. E., \& Bingham, J. B. (2011). When Employees Do Bad Things for Good Reasons: Examining Unethical Pro-Organizational Behaviors. Organization Science, 22, 541-815. https://doi.org/10.1287/orsc.1100.0559

Umphress, E. E., Bingham, J. B., \& Mitchell, M. S. (2010). Unethical Behavior in the Name of the Company: The Moderating Effect of Organizational Identification and Positive Reciprocity Beliefs on Unethical Pro-Organizational Behavior. Journal of Applied Psychology, 95, 769-780. https://doi.apa.org/doi/10.1037/a0019214

Vadera, A. K., Pratt, M. G., \& Mishra, P. (2013). Constructive Deviance in Organizations Integrating and Moving Forward. Journal of Management, 39, 1221-1276. https://journals.sagepub.com/doi/10.1177/0149206313475816\#

Van Scotter, J. R., \& Motowidlo, S. J. (1996). Interpersonal Facilitation and Job Dedication as Separate Facets of Contextual Performance. Journal of Applied Psychology, 81, 525-531. https://doi.apa.org/doi/10.1037/0021-9010.81.5.525

Victor, B., \& Cullen, J. B. (1987). A Theory and Measure of Ethical Climate in Organizations. In W. C. Frederick (Ed.), Research in Corporate Social Performance (pp. 57-71). Greenwich, CT: JAI Press.

Wallace, J. C., Popp, E., \& Mondore, S. (2006). Safety Climate as a Mediator between 
Foundation Climates and Occupational Accidents: A Group-Level Investigation. Journal of Applied Psychology, 91, 681-688.

https://doi.apa.org/doi/10.1037/0021-9010.91.3.681

Wan, Y. F., \& Zhu, Y. (2006). An Introduction of Researches and Theory of Organizational Ethics Climate. Advances in Psychological Science, 14, 300-308.

Wimbush, J. C., Shepard, J. M., \& Markham, S. E. (1997). An Empirical Examination of the Relationship between Ethical Climate and Ethical Behavior from Multiple Levels of Analysis. Journal of Business Ethics, 16, 1705-1716. https://doi.org/10.1023/A:1017952221572

Yuan, L., \& Liu, Z. Y. (2016). The Relationship between Organizational Ethical Climate and Employee Voice Behavior under the Perspective of Psychological Safety. Human Resources Development of China, No. 5, 48-54.

Zhang, S. L. (2014). An Empirical Study on the Impact of Organizational Ethical Climate on Organizational Citizenship Behavior. Doctoral Dissertation, Changsha: Central South University.

Zhang, Y. J., Zhang, P. C., \& Zhao, J. (2017). The Relationship between Paternalistic Leadership and Unethical Pro-Organizational Behavior: Traditionality as a Moderator. Nankai Business Review, 20, 169-179. 